\title{
Prevalence of undernutrition and risk factors of severe undernutrition among children admitted to Bugando Medical Centre in Mwanza, Tanzania
}

Maimuna M. Ahmed', Adolfine Hokororo', Benson R. Kidenya², Rogatus Kabyemera ${ }^{1}$ and Erasmus Kamugisha ${ }^{2 *}$

\begin{abstract}
Background: Malnutrition is a major public health problem in developing countries including Tanzania, contributing up to $50 \%$ of under-five mortality. East Africa region was among the three United Nations (UN) subregions with the highest prevalence of stunting in 2011. In resource limited countries, the available little resources in hospitals are likely to be used focusing the primary clinical problem that led to admission of children leaving moderate and mild malnutrion unattended. This work was conducted to determine the prevalence of under-nutrition and risk factors associated with severe malnutrition among undernourished children aged 6-60 months admitted to Bugando Medical Centre (BMC) paediatric wards.
\end{abstract}

Method: This was a hospital-based cross sectional study where by 720 children were screened in order to determine their nutritional status. Data were collected through measurement of weight/length or height, mid upper arm circumference (MUAC) and interpretation was done using Z-score (mild malnutrition $\leq 1 \mathrm{SD}$, moderate malnutrition $\leq 2 \mathrm{SD}$ and severe malnutrition $\leq 3 \mathrm{SD}$ ). The socio-demographic data were obtained using a questionnaire that was completed by interviewing children's parents/caregiver.

Results: Out of 720 screened children, 402 (55.8\%) were undernourished. Severe malnutrition was found in 178 (24.7\%) children and among these 97 (54.5\%) had marasmus. Risk factors associated with severe malnutrition were children with age less than 2 years, lack of vaccination, taking unbalanced diet, low maternal education and single parent, with $p$-value $(<0.001,<0.001,<0.001,0.02,<0.001)$ respectively.

Conclusion: This study show a high prevalence of malnutrition in hospitalized children and the majority was marasmic. The risk factors associated with severe malnutrition were described. We recommend improving the screening for undernutrition in all admitted patients so that proper management of this problem can be done concurrently with the primary clinical disease that led to admission.

Keywords: Malnutrition, Marasmus, Underfives

Abbreviations: BMC, Bugando Medical centre; Cl, Confidence interval; EPI, Essential program for immunization; MUAC, Mid-upper arm circumference; OR, Odds ratio; SD, Standard deviation; TB, Tuberculosis; TDHS, Tanzania demographic and Health Survey; UN, United Nations; WHO, Word Health Organisation

\footnotetext{
* Correspondence: erasmuskamugisha@yahoo.com

2Department of Biochemistry and Molecular Biology, Catholic University of

Health and Allied Sciences, P.O. Box 1464, Mwanza, Tanzania

Full list of author information is available at the end of the article
} 


\section{Background}

Malnutrition is still a problem in the developing world. Its prevalence among under-fives is $41 \%$ with an estimated 230 million (39 \%) children being chronically malnourished [1, 2]. East Africa was among three UN subregions with highest prevalence of stunting among all United Nations subregions in 2011 [3]. In this study it was reported that East Africa was the second UN subregion with a prevalence of $42 \%$ being second to South-central Asia. [3] In resource limited countries, the available little resources in hospitals are likely to be used focusing the primary clinical problem that led to admission of children, leaving moderate and mild malnutrion unattended. Nutritional support and parents counseling are essential aspect of the management of children admitted to hospital. [4]. Although there is a lot of data on the prevalence of malnutrition in the community, data on the prevalence of malnutrion in hospitalized children especially from Africa is scarce. Abrupt weaning and lack of breast feeding contribute to malnutrition in the first year of life, while inadequate intake of protein and calories in the second year of life [5]. In developing countries, malnutrition contributes to more than $50 \%$ of under-five mortality [6-9]. Malnourished survivors are usually left with mental developmental delay, poor school performance and reduced intellectual achievements $[2,6,10]$.

According to the Tanzania Health and Demographic Survey (TDHS) of 2010, moderate malnutrition ( $\leq 2 \mathrm{SD})$ was found in $5 \%$ and $1 \%$ of the surveyed children were severely wasted $(\leq 3 \mathrm{SD})$. In the same survey, the prevalence of moderate and severe malnutrition in Mwanza region were $3.9 \%$ and $1.3 \%$ respectively [11].

In view of these findings, this study was designed to find the prevalence of under-nutrition children admitted in paediatrics wards of Bugando Medical centre. The risk factors of severe undernutrition among admitted children with malnutrition was also investigated. The real prevalence of the hospital setting in this area were not known, and it is expected that children admitted for various illnesses might be suffering from an underlying undernutrition.

\section{Methods}

\section{Study design, area and population}

This was a hospital-based cross-sectional study conducted at Bugando Medical Centre (BMC) which is one of the four tertiary referral, research and teaching hospitals in Tanzania serving the northwestern part. The pediatric department of BMC is divided into four subunits namely; general pediatric ward, pediatric semi-intensive care unit, neonatal unit and malnutrition unit. The malnutrition unit admits severely malnourished children and in this ward, specialized care and feeding are strictly supervised by both nurses and doctors. In this study all children admitted in the paediatric department, aged 6 60 month, were screened for their nutritional status and those found to be undernourished were included after parents/caretaker signed an informed consent forms. Children with known sickle cell disease, cerebral palsy and congenital heart diseases were excluded from this study.

\section{Demographic and clinical information}

Information regarding the socio-demographic data and past medical history was collected using a pretested structured questionnaire. Feeding history was established if the child was still breast-feeding, ever breastfed or not and the duration of breastfeeding. When complementary feeding was started, types of complementary food, the number of feeds in a day and the amount which was given were documented. Unbalanced diet was considered when one or more of the major groups of food were missing in the diet. The major food groups considered were carbohydrates, proteins, fats, minerals and vitamins and water.

\section{Clinical work-up}

All the admitted children aged 6-60 months with any clinical condition, were screened in order to determine their nutritional status. Anthropometric measurements such as weight for height or length and mid-upper arm circumference (MUAC) were used in order to categorize the degree of malnutrition. Infants under two years of age were weighed using a $25 \mathrm{~kg}$ Salter hanging scale (CMS Weighing equipment, High Holborn, London United Kingdom), while those above two years of age were weighed while standing on the Salter digital floor scale (CMS Weighing equipment, High Holborn, London United Kingdom). MUAC of $12.5-13.5 \mathrm{~cm}$ were categorized as mild malnutrition, 11.0 to $12.5 \mathrm{~cm}$ was regarded as moderate malnutrition and less than $11 \mathrm{~cm}$ were considered as severe malnutrition. Children with weight for length/height $\mathrm{Z}$ score of $\leq 1 \mathrm{SD}$ were categorized as mild malnutrition, while $\leq 2 \mathrm{SD}$ was considered moderate malnutrition and severe malnutrition were those from $\leq 3$. Convenient serial sampling method was used to enroll all children admitted. Data was entered into the computer using Microsoft Excel 2007, cleaned and analyzed using STATA version 11 (college station, Texas), and thereafter summarized in frequency tables. To determine the risk factors of severe malnutrion in under-nutrition, we preformed univariate followed by multivariate logistic regression analysis. Factors with a $p$-value less than 0.1 on univariate logistic regression analysis were subjected to multivariate logistic regression. Factors with $p$-value of less than 0.05 were considered to be statistically significant. 


\section{Results}

\section{Prevalence of under-nutrition}

From September 2012 to January 2013, a total of 738 children aged between $6-60$ months were admitted in pediatric wards at BMC and were all screened for undernutrition. Among them, 18 were excluded from the study due to cerebral palsy. Of the remaining 720 who were included in the analysis, 402 (55.8 \%) children were undernourished. Among 720 participants, 178 (24.7\%) had severe malnutrition and 97 (54.5\%) of them were marasmic. (Fig. 1). Further analysis included only 402 children with malnutrition.

\section{Social demographic characteristics}

Most of the children were residing in Mwanza region, (352, 87.6\%), male children were 229 (57\%) and those aged 13 - 24 months were 147 (36.6\%). The majority, 358 (89.1\%) completed vaccination as per WHO expanded programme on immunization (EPI) schedule and a large group of children, 267 (66.4\%), were weaned less than six months (Table 1).
Risk factors for severe malnutrition among undernourished children

In univariate logistic regression analysis, age group 612 months and 13-24 months were both significantly associated with severe malnutrition $(p<0.001)$ compared to children aged more than 2 years. Other factors that were significantly associated with severe malnutrition on univariate analysis were eating unbalanced diet $(\mathrm{OR}=$ 7.1; $95 \% \mathrm{CI}=2.7-18.4 ; p=<0.001$ ), incomplete or lack of vaccination $(\mathrm{OR}=3.4 ; 95 \% \mathrm{CI}=1.7-6.8 ; p=<0.001)$ and children with a single parent $(\mathrm{OR}=3.9 ; 95 \% \mathrm{CI}=$ $2.3-6.6 ; p=<0.001$ ). When these factors (type of diet, vaccination status and parenthood) were subjected to multivariate logistic regression analysis, they all remained significantly associated with severe malnutrition $(\mathrm{OR}=3.9$, $95 \% \mathrm{CI}=1.5-10.6, p=0.007 ; \mathrm{OR}=2.1,95 \% \mathrm{CI}=1.1-$ $4.5, p=0.042$; $\mathrm{OR}=3.4,95 \% \mathrm{CI}=1.9-5.9, p=<0.001)$ respectively (see Table 2). Also age group 6-12 months and $13-24$ months remained statistically significant in multivariate logistic regression ( $p=<0.001$ and 0.001 respectively)

In univariate logistic regression analysis, children of parents with primary education was significantly associated

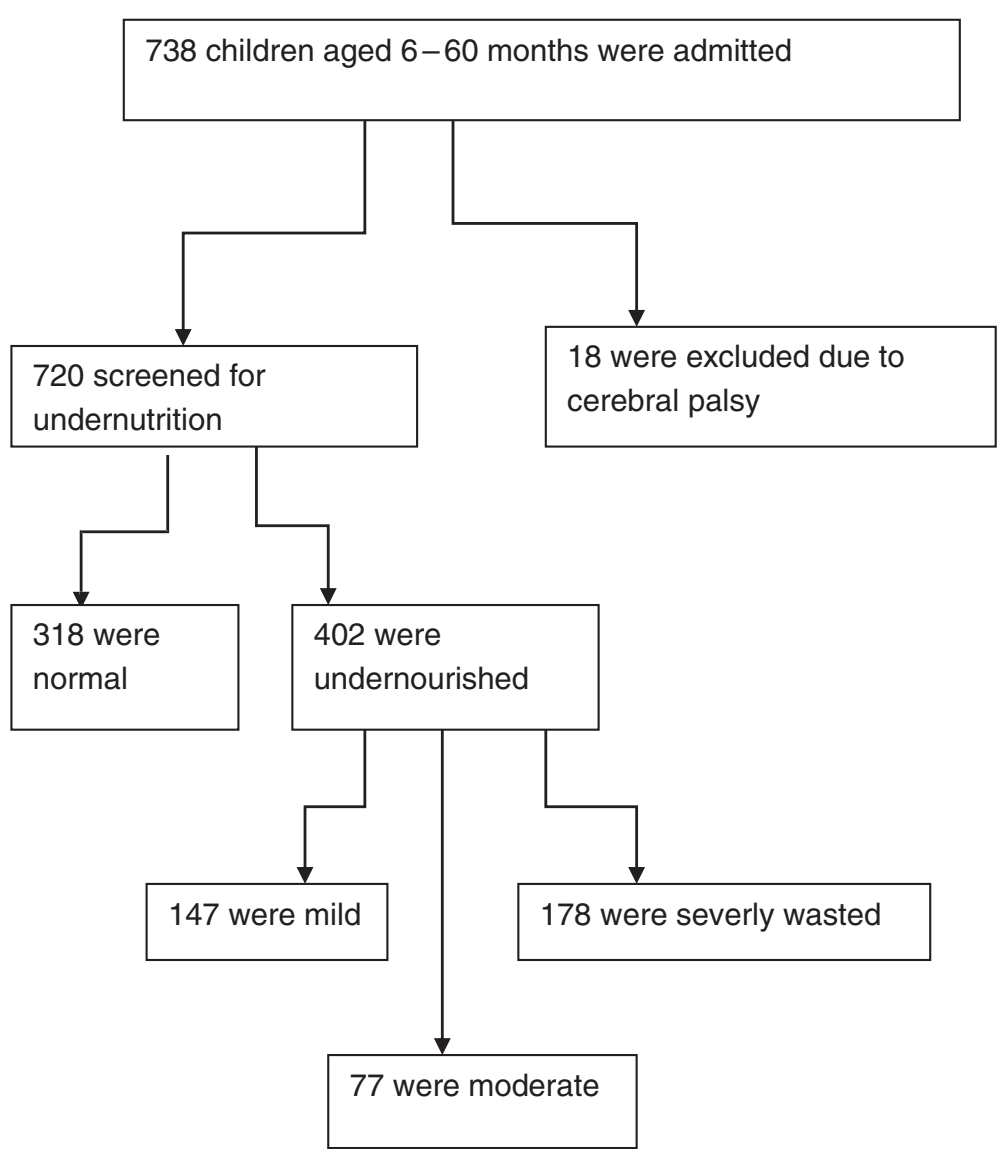

Fig. 1 Study profile showing the screening process of undernourished children 
Table 1 Social demographic characteristics of 402 undernourished children admitted at bugando medical centre

\begin{tabular}{|c|c|c|}
\hline Characteristics & Number $(N=402)$ & Percentage (100 \%) \\
\hline \multicolumn{3}{|l|}{ Child age (Month) } \\
\hline $6-12$ & 128 & 31.8 \\
\hline $13-24$ & 147 & 36.6 \\
\hline$\geq 25$ & 127 & 31.6 \\
\hline \multicolumn{3}{|l|}{ Child Sex } \\
\hline Male & 229 & 57.0 \\
\hline Female & 173 & 43.0 \\
\hline \multicolumn{3}{|c|}{ Vaccination of the child } \\
\hline Complete & 358 & 89.1 \\
\hline Incomplete & 41 & 10.2 \\
\hline None & 3 & 0.7 \\
\hline \multicolumn{3}{|c|}{ Age of weaning(month) } \\
\hline$<6$ & 267 & 66.4 \\
\hline$\geq 6$ & 135 & 33.6 \\
\hline \multicolumn{3}{|l|}{ Caretaker education } \\
\hline Non-formal & 83 & 20.6 \\
\hline Primary & 266 & 66.2 \\
\hline Secondary & 36 & 9.0 \\
\hline College/university & 17 & 4.2 \\
\hline \multicolumn{3}{|l|}{ Parents Occupation } \\
\hline Peasant & 237 & 58.9 \\
\hline Employed & 49 & 12.2 \\
\hline Business & 116 & 28.9 \\
\hline \multicolumn{3}{|l|}{ Parental Marital status } \\
\hline Single & 53 & 13.2 \\
\hline Married & 318 & 79.1 \\
\hline Divorced & 24 & 6.0 \\
\hline Widowed & 7 & 1.7 \\
\hline \multicolumn{3}{|l|}{ Family Size } \\
\hline$<6$ & 294 & 73.1 \\
\hline$\geq 6$ & 108 & 26.9 \\
\hline
\end{tabular}

with severe malnutrition compared to those of parents with college or university education $(\mathrm{OR}=4.3$; $95 \% \mathrm{CI}=1.2-15.4 ; P=0.02)$. However, this factor was not statistically significant in multivariate logistic regression analysis as shown in (Table 2).

\section{Discussion}

The overall prevalence of undernutrition in our hospital was high. The prevalence is higher than $34 \%$ which was found among hospitalized paediatrics patients in South Africa [12]. The prevalence is higher than the community prevalence of malnutrition in Tanzania (TDHS). This could be explained by the fact that this study was done in the referral hospital which is the only hospital in Tanzania's lake zone with the malnutrition unit. Nearly a quarter of the participants had severe malnutrition. This is closely similar to the community studies done in Malawi and Sudan where their prevalence were $22 \%$ and $27.3 \%$ respectively $[13,14]$. Among the children with severe malnutrition, slightly over half of them had marasmus, similarly to the study done in Kenya where $57.6 \%$ had marasmus [15]. We did not find a higher proportion of children with kwashiorkor, probably due to the fact that majority of the participants live in close proximity to lake Victoria where they can easily access protein containing foods like fish though affordability may limit its access. Previous studies done in other parts of Africa where common food is maize, yams and banana with limited access to protein rich food reported the prevalence of kwashiorkor ranging from $35 \%$ to $86 \%[5,15-18]$.

Furthermore, these studies were done in children aged less than 2 years who require higher calories for metabolism and growth. Malnutrition also significantly lowers immunological responses and hence a higher possibility of having a vicious circle between malnutrition and recurrent infections. Our finding that an association exists between lower age and malnutrition is further supported by previous studies done in Sudan, Nigeria and Bangladesh [13, 17, 19].

Having a single parent was strongly associated with severe malnutrition in both univariate and multivariate logistic regression analysis. This finding is similar to results from studies done in Botswana and Congo where the chances of malnutrition were decreasing when both parents were living together $[20,21]$. Single parents may be struggling to earn more income in order to sustain their children.

Children who were fed on unbalanced diet had a higher chance of developing malnutrition since they are more likely to live in a low social economic environment with limited access to nutritious food. Food for majority of children is still a challenge; these children are not getting enough food not only in case of amount but also poor in quality so they are prone to all types of malnutrition. A Study done in Congo observed that majority of under-fives especially in rural areas were not taking balanced diet [21].

Under-fives, when vaccinated, have reduced chances of acquiring infections like pulmonary $\mathrm{TB}$, diarrheal disease, measles and severe pneumonia, all of which are clinical conditions that can lead to malnutrition. Findings in this study showed that children who were not vaccinated or had incomplete vaccination had higher chances of having severe malnutrition in both univariate and multivariate analysis which is supported by results from a Ugandan study [22]. It should also be noted that, the lack of vaccination may be related to lack of care, 
Table 2 Risk factors for severe malnutrition among undernourished children admitted at Bugando Medical Centre

\begin{tabular}{|c|c|c|c|c|c|c|}
\hline \multirow[t]{2}{*}{ Risk factors } & \multicolumn{2}{|l|}{ Malnutrition } & \multicolumn{2}{|l|}{ Unadjusted } & \multicolumn{2}{|l|}{ Adjusted } \\
\hline & Severe $(N=178) n(\%)$ & Mild and moderate $(N=224) n(\%)$ & $\mathrm{OR}[95 \% \mathrm{Cl}]$ & $P$ - value & OR[95 \% Cl] & $P$ - value \\
\hline \multicolumn{7}{|l|}{ Age } \\
\hline$\geq 25$ & $32(25.2)$ & $95(74.8)$ & 1 & & & \\
\hline $13-24$ & $78(53.1)$ & $69(46.9)$ & $3.4(2.0-5.6)$ & $<0.001$ & $2.7(1.5-4.6)$ & $<0.001$ \\
\hline $6-12$ & $68(53.1)$ & $60(46.9)$ & $3.4(2.0-5.7)$ & $<0.001$ & $2.5(1.4-4.5)$ & 0.001 \\
\hline \multicolumn{7}{|l|}{ Vaccination } \\
\hline Yes & $147(41.1)$ & $211(58.9)$ & 1 & & & \\
\hline No/incomplete & $31(70.5)$ & $13(29.5)$ & $3.4(1.7-6.8)$ & $<0.001$ & $2.1(1.1-4.5)$ & 0.042 \\
\hline \multicolumn{7}{|l|}{ Early-weaning } \\
\hline No & $61(45.2)$ & $74(54.8)$ & 1 & & & \\
\hline Yes & $117(43.8)$ & $150(56.2)$ & $0.9(0.6-1.4)$ & 0.795 & - & - \\
\hline \multicolumn{7}{|l|}{ Balanced diet } \\
\hline Yes & $5(11.6)$ & $38(88.4)$ & 1 & & & \\
\hline No & $173(48.2)$ & $186(51.8)$ & $7.1(2.7-18.4)$ & $<0.001$ & $3.9(1.5-10.6)$ & 0.007 \\
\hline \multicolumn{7}{|l|}{ Parent education } \\
\hline College/University & $3(17.6)$ & $14(82.4)$ & 1 & & $1.0(0.2-4.6)$ & \\
\hline Secondary & $11(30.6)$ & $25(69.4)$ & $2.1(0.5-8.6)$ & 0.32 & $2.4(0.6-9.2)$ & 0.990 \\
\hline Primary & $128(48.1)$ & $138(51.9)$ & $4.3(1.2-15.4)$ & 0.02 & $2.0(0.5-8.4)$ & 0.193 \\
\hline Non formal & $36(43.4)$ & $47(56.6)$ & $3.6(0.9-13.4)$ & 0.06 & & 0.297 \\
\hline \multicolumn{7}{|l|}{ Family Income (month) } \\
\hline$\geq 50,000\left(\right.$ Tsh* $^{*}$ & $53(39.8)$ & $80(60.2)$ & 1 & & & \\
\hline$<50,000\left(\right.$ Tsh$\left.^{*}\right)$ & $125(46.5)$ & $144(53.5)$ & $1.3(0.9-1.9)$ & 0.209 & - & - \\
\hline \multicolumn{7}{|l|}{ Single Parent } \\
\hline No & $119(37.4)$ & $199(62.6)$ & 1 & & & $<0.001$ \\
\hline Yes & 59 (70.2) & 25 (29.8) & $3.9(2.3-6.6)$ & $<0.001$ & $3.4(1.9-5.9)$ & \\
\hline
\end{tabular}

${ }^{*} T s h$ is Tanzanian shillings

families with major problems in education, lower social economic status and single parents, all of which may lead to undernutrition. Previous studies had shown that women who didn't attend school and ones with primary level of education had a higher chance of their children being malnourished compared to educated mothers who have a higher tendency of health seeking behavior $[14,19,21]$. Similar to previous studies, we did not find any association between severe malnutrition and either sex of the child, parents' occupation, family income or family size $[13,20,21,23]$.

\section{Conclusions}

High prevalence of undernutrition was observed in our setting and the majority of severely malnourished children were marasmic. Children with single parents, who were fed on unbalanced diet, unvaccinated or who were partially vaccinated and those whose parents had lower level of education were more likely to be severely malnourished. We recommend routine screening for malnutrition to be done in every child who attends the hospital and nutritional counseling be done to their parents in order to prevent their children from severe malnutrition.

\section{Acknowledgements}

Authors wishes to acknowledge and thank thenursing staff of the Bugando Medical Centre Paediatric wards for their suggestions and moral support during data collections and lastly the parents and children who participated in the study.

\section{Funding}

This study was funded by the research funds from Ministry of Health and Social Welfare and the Department of Microbiology and Immunology of the Catholic University of Health and Allied Sciences given to MHA.

\section{Availability of data and materials}

Important data for this paper are contained in the manuscript. Individual patients' data are not shared in this work due to ethical reasons. Authors did not include data sharing clearance during the ethical approval.

\section{Authors' contributions}

MHA, EK, AH and RK designed the study. MHA, AH and RK carried out data collection. MHA, EK, AH, BRK and RK were involved in data analysis and interpretation of results. All authors were fully involved in writing the manuscript and all have approved the final manuscript for submission. 


\section{Competing interests}

All authors declares that they have no competing interests.

\section{Consent for publication}

Not applicable.

\section{Ethics and consent to participate}

Permission to conduct the study was sought from the Catholic University of Health and Allied Sciences (CUHAS) and BMC joint ethics committee. An informed consent form was signed by parents/care takers before conducting the study. All children with malnutrition were treated according to $\mathrm{WHO}$ malnutrition treatment guideline. Permission to publish the paper was also obtained from the CUHAS/BMC joint ethics committee.

\section{Author details}

'Department of Paediatrics and Child Health, Bugando Medical Centre, P.O Box 1370, Mwanza, Tanzania. ${ }^{2}$ Department of Biochemistry and Molecular Biology, Catholic University of Health and Allied Sciences, P.O. Box 1464, Mwanza, Tanzania.

Received: 29 October 2015 Accepted: 11 August 2016

Published online: 17 August 2016

\section{References}

1. UNICEF. The state of the world's children. New York: UNICEF; 2000.

2. De Onís M, Monteiro C, Akré J, Glugston G. The worldwide magnitude of protein-energy malnutrition: an overview from the WHO Global Database on Child Growth. Bull World Health Organ. 1993;71(6):703-12.

3. Black RE, Victora CG, Walker SP, Bhutta ZA, Christian P, Onis M, Ezzati M, McGregor SG, Katz J, Martorell R, Uauy R. Maternal and child undernutrition in low-income countries. Lancet. 2013:382:427-51.

4. Joonsten KFM, Hulst JM. Prevalence of malnutrition in paediatric hospital patients. Curr Opin Pediatr. 2008:20:590-6.

5. Collins S, Dent N, Binns P, Bahwere P, Sadler K, Hallam A. Management of severe acute malnutrition in children. Lancet. 2006;368:1992-2000.

6. Sunguya B. Effects of Infections on Severely Malnourished Children in Kilifi-Mombasa and Dar es Salam : A Comprehensive Study. Dar es salaam Med Stud J. 2006;14(1):27-35.

7. Okomo UA, Garba D, Fombah AE, Secka O, Ikumapayi UN, Udo JJ, et al. Bacterial Isolates and Antibiotic Sensitivity among Gambian Children with Severe Acute Malnutrition. Int J Pediatr. 2011;2011:825123.

8. Goal MD, Africa S, Development H, Office R. Sub-Saharan Africa - the human costs of the 2015 "business-as-usual" scenario Child mortality. 2005;1-4.

9. Smith LC, El Obeid HHJ AE. The geography and causes of food insecurity in developing countries. Agri Econ. 2000;22(2):199-215.

10. Lisa C, Smith LH. Explaining Child Malnutrition in Developing Countries A Cross- Country Analysis. Washington, D.C.: International food Policy research institute; 2000

11. Heikens GT, Bunn J, Amadi B, Manary M, Chhagan M, Berkley J, et al. Case management of HIV-infected severely malnourished children: challenges in the area of highest prevalence. Lancet. 2008;371(9620):1305-7.

12. Marino LV, Goddad E, Workman L. Determining the prevalence of malnutrition in hospitalized paediatric patients. S Afr Med J. 2006;96:993-5.

13. Mahgoub SEO, Nnyepi M, Bandeke T. Factors Affecting Prevalence of Malnutrittion among Children under Three Years of Age in Botswana. Afr J Food Agr Nutr Dev. 2006;6(1):1-15.

14. Mahgoub HM, Adam I. Morbidity and mortality of severe malnutrition among Sudanese children in New Halfa Hospital, Eastern Sudan. Trans R Soc Trop Med Hyg. 2012;106(1):66-8.

15. USAID. Nutrition of Young Children and Mothers in Malawi: Findings from the 2004 malawi demographic and Health Survey. African Nutrition Chartbooks. 2004. p. 1-81

16. Maitland K, Berkley JA, Shebbe M, Peshu N, English M, Newton CRJC. Children with severe malnutrition: can those at highest risk of death be identified with the WHO protocol? PLOS Med. 2006;3(12):e500.

17. Irena AH, Mwambazi M, Mulenga V. Diarrhea is a major killer of children with severe acute malnutrition admitted to inpatient set-up in Lusaka, Zambia. Nutr J. 2011:10(1):110.

18. Ubesie AC, Ibeziako NS, Ndiokwelu Cl, Uzoka CM, Nwafor CA. Under-five protein energy malnutrition admitted at the University of Nigeria Teaching Hospital, Enugu: a 10 year retrospective review. Nutr J. 2012;11(1):43.
19. Jobiba C, Andrew T, Theresa B, Catherine MPF. The impact of HIV on mortality during in-patient rehabilitation of severely malnourished children in Malawi. Trans R Soc Trop Med Hyg. 2008;102:639-44.

20. National Bureau of statistics (NBS) Tanzania I marco. Tanzania Demographic and Health Survey 2010. Dar es Salaam Tanzania: NBS and ICF Marco; 2011.

21. Israt R, Sekander Hayat Khan M. Factors causing malnutrition among under five children in Bangladesh. Pakistan J Nutr. 2006;5(6):558-62.

22. Kandala N-B, Madungu TP, Emina JBO, Nzita KPD, Cappuccio FP. Malnutrition among children under the age of five in the Democratic Republic of Congo (DRC): does geographic location matter? BMC Public Health. 2011;11(1):261.

23. Owor M, Tumwine JK, Kikafunda JK. Socio-economic Risk Factors for Severe Protein Energy Malnutrition Among Children in Mulago Hospital, Kampala. East Afr Med J. 2000;77(9):471-5.

\section{Submit your next manuscript to BioMed Central and we will help you at every step:}

- We accept pre-submission inquiries

- Our selector tool helps you to find the most relevant journal

- We provide round the clock customer support

- Convenient online submission

- Thorough peer review

- Inclusion in PubMed and all major indexing services

- Maximum visibility for your research

Submit your manuscript at www.biomedcentral.com/submit
) Biomed Central 